\title{
Effect of genotype, embryo maturity and culture medium on in vitro embryo germination of Sri Lankan coconut (Cocos nucifera L.) varieties
}

\author{
V.R.M. Vidhanaarachchi ${ }^{1^{*}}$, W.C. Suranjith ${ }^{2}$ and T.R. Gunathilake ${ }^{1}$ \\ ${ }^{\prime}$ Tissue Culture Division, Coconut Research Institute, Bandirippuwa Estate, Lunuwila. \\ ${ }^{2}$ Quality Assurance Department, CBL Foods International Pvt. Ltd., Habarakada Road, Ranala.
}

\begin{abstract}
Poor in vitro germination of embryos of exotic varieties was reported as one of the major constraints faced during coconut germplasm exchange programmes. In this study, the effect of genotype, embryo maturity and culture medium on in vitro germination of coconut embryos was investigated. A significant effect $(\mathrm{p}<0.05)$ of genotype on in vitro germination was observed between the selected cultivars, San Ramon Tall (SNRT) (77.48 \%), Sri Lanka Red Dwarf (SLRD) (67.28 \%), Sri Lanka Green Dwarf (PGD) (71.85 \%) and King Coconut (RTB) (52.5\%). Embryo germination percentages were improved in solid media $(91.66 \%$ and $92.22 \%$ in $75 \mathrm{~g} / \mathrm{L}$ and $60 \mathrm{~g} / \mathrm{L}$ sucrose respectively, $\mathrm{p}<0.05)$ than in liquid media ( $56.66 \%$ and $60.46 \%$ in $75 \mathrm{~g} / \mathrm{L}$ and $60 \mathrm{~g} / \mathrm{L}$ sucrose, respectively) and the sucrose concentration has no effect on germination of SLRD embryos. Furthermore, maturity of the nut significantly affected the germination $(\mathrm{p}<0.05)$ of embryos of PGD and the highest in vitro embryo germination was achieved by culturing embryos of the 12 month old bunch (97.67\%), while the lowest was observed in the 10 month old bunch (52.17\%). Addition of growth hormones favoured root growth of in vitro raised SLRD plants with a significant increase in the number of primary roots and the number of leaves $(\mathrm{p}<0.05)$ when $10 \mu \mathrm{M}$ BAP, $10 \mu \mathrm{M}$ Kinetin and $200 \mu \mathrm{M}$ NAA were added to the embryo culture medium.
\end{abstract}

Keywords: Coconut, cultivars, embryo culture, in vitro embryo germination, shoot and root growth.

\section{INTRODUCTION}

Conservation of coconut genetic resources is of vital importance for present and future breeding programmes for maintaining the genetic diversity (Weerakoon et al.,
2002). Based on loss of palms, the rate of reduction of the existing coconut genotypes in Sri Lanka was estimated to be around $2 \%$ annually, leading to genetic erosion. The main causes of genetic erosion were land fragmentation for urbanisation/industrialisation and replacement of locally adapted old coconut plantations with improved coconut cultivars, which has a narrow genetic base. Biotic and abiotic factors such as drought and cyclones have also been identified as causes of the genetic erosion to a lesser extent. Therefore, systematic collection and conservation of coconut germplasm at the Coconut Research Institute, Sri Lanka (CRISL) was initiated in 1984 in order to conserve the existing germplasm and to obtain locally adapted materials for future breeding programmes. However, DNA based germplasm characterisation studies carried out at the CRISL revealed that the genetic base of the available coconut gene pool in Sri Lanka is narrow, and therefore further improvement of coconut by utilising only locally available materials is limited (Perera et al., 1999). Moreover, it was also revealed that the South-East Asia and Pacific regions have a wider genetic diversity when compared with the South Asian and African regions (Perera et al., 2003). Therefore, it was decided that incorporation of exotic germplasm, especially from South-East Asia and Pacific is important for further improvement of coconut in Sri Lanka.

Coconut is one of the largest seed producing plant species within the Plant Kingdom. Quick germination can be observed after maturation, which negatively affect the collection and exchange of coconut germplasm among countries. The introduction of exotic germplasm 
has also been restricted by quarantine regulations considering possible inadvertent introduction of many pests and lethal diseases prevalent in other coconut growing countries.

Therefore, coconut germplasm exchange is possible only as embryos or embryo containing endosperm plugs and raising of seedlings through in vitro embryo culture technique, which prevent the introduction of pests and diseases inadvertently (Assy-Bah et al., 1987). Mature embryos of $10-12$ month old nuts are collected, sterilised and pre-cultured in storage medium in cryovials individually. These cryovials can be hand carried or be sent by air mail through courier services to recipient countries. Once they arrive at the recipient laboratories the embryos are transferred to normal embryo germination medium and raised to plants, acclimatised and field planted. One of the major drawbacks in germplasm exchange programmes is poor germination of embryos of some exotic genotypes, and the possible reasons identified are the effect of genotypes, maturity of nuts and long storage time during collection and transport (Cueto et al., 2012). These should be minimised to achieve an acceptable level of embryo germination in order to develop a viable germplasm exchange programme. Therefore, this study was focused on evaluating the genotype effect on in vitro embryo germination and possible improvements to the germination medium. The effect of nut maturity on in vitro germination of embryos was also evaluated. In addition to the above drawbacks at the germination stage, poor root growth of in vitro raised seedlings is one of the reasons for low survival rates at the acclimatisation stage. Therefore, to improve root growth of in vitro seedlings different auxin treatments were tested with plants four (04) months after germination.

\section{METHODOLOGY}

\section{Materials}

Four locally grown coconut cultivars, namely, Sri Lanka Red Dwarf (SLRD), Sri Lanka Green Dwarf (PGD), San Ramon Tall (SNRT) and King Coconut (RTB) were used in this experiment. Mature nuts were harvested from 12 month old bunches unless otherwise specified, de-husked and split opened. Endosperm plugs were extracted using a cork borer. The extracted endosperm plugs were properly rinsed out $4-5$ times in tap water after adding a few drops of liquid soap. Zygotic embryos were dissected from endosperm plugs with a scalpel blade and collected (Figure 1).

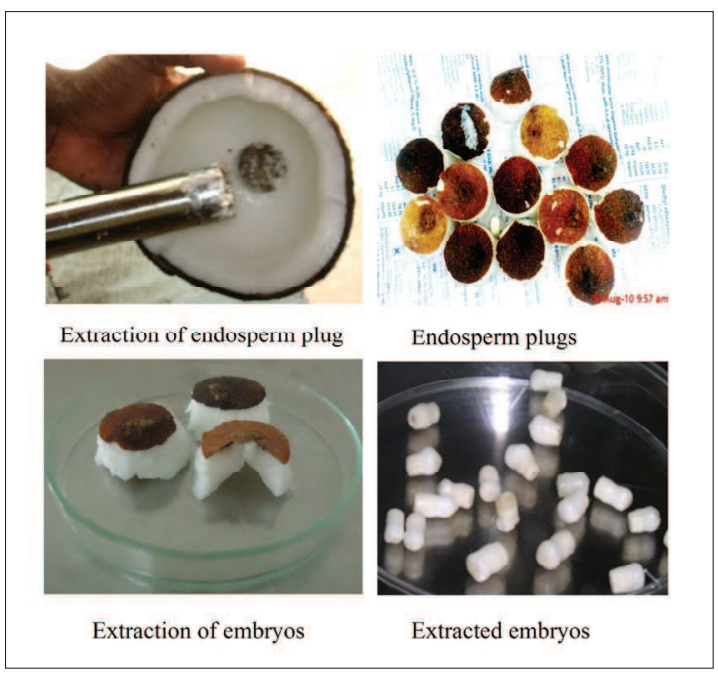

Figure 1: Collection of coconut embryos for in vitro culture

\section{Embryo culture}

Surface sterilisation of the embryos was carried out using newly prepared $5 \%$ bleach solution with a few drops of liquid soap followed by washing $4-5$ times with sterilised distilled water. The sterilised embryos were then cultured on modified $\mathrm{Y}_{3}$ medium (Karunaratne et al., 1985) and incubated under dark conditions at $28^{\circ} \mathrm{C}$ for 2 months. Germinated embryos were transferred to light with $16 \mathrm{hrs}$ photoperiod (Temperature $28 \pm 1{ }^{\circ} \mathrm{C}$,

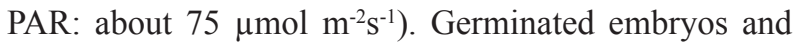
plants were sub-cultured onto fresh media at every $5-6$ week intervals.

\section{Effect of genotype on in vitro embryo germination}

Embryo germination of Sri Lanka Red Dwarf (SLRD), Sri Lanka Green Dwarf (PGD), San Ramon Tall (SNRT) and King Coconut (RTB) were evaluated. Four replicates consisting of 20 embryos were used from each cultivar and modified Eeuwens $\mathrm{Y}_{3}$ medium (Karunaratne et al., 1985) was used as the culture medium.

\section{Effect of germination medium on in vitro embryo germination of SLRD}

Modified Eeuwens $\mathrm{Y}_{3}$ medium (Karunaratne et al., 1985) was used as the basal culture medium with two levels of sucrose (60 g/L and $75 \mathrm{~g} / \mathrm{L}$ ), and solid (by adding $0.7 \%$ agar) and liquid states of medium were combined to get four different treatments. Each treatment was replicated 6 times with 15 embryos per each replicate. Embryos of SLRD were used as the explants and embryo germination and plant development were recorded. 
Effect of embryo maturity on in vitro germination of PGD

Zygotic embryos were obtained from PGD to determine the most suitable maturity stage of nuts for embryo culture. Nuts were obtained from 10,11 and 12 month old bunches (considering the last opened inflorescence as 0 ) and the embryos were cultured in modified Eeuwens $\mathrm{Y}_{3}$ medium (Karunaratne et al., 1985). Two replicates with 20 embryos per replicate were used for each treatment and embryo germination was recorded.

\section{Effect of hormones on root development of SLRD}

In vitro raised plants of SLRD were used to evaluate the effect of indoleacetic acid (IAA), benzyl amino purine (BAP), kinetin and naphthaleneacetic acid (NAA) on root development. Cutting of initial primary root of 4 months old in vitro grown plants was done (leaving about $0.5-1 \mathrm{~cm}$ root) as practiced in coconut embryo culture (Weerakoon et al., 2002). Root development in 3 treatments viz., dipping shoots in IAA solution $\left(10^{-4} \mathrm{M}\right)$ for 3 days followed by transfer to normal embryo culture media (Fernando \& Gamage, 1995); culturing in $10 \mu \mathrm{M}$ BAP and $10 \mu \mathrm{M}$ kinetin added media for 1 month followed by transfer to $200 \mu \mathrm{M}$ NAA added media; culturing in $10 \mu \mathrm{M}$ BAP, $10 \mu \mathrm{M}$ kinetin and $200 \mu \mathrm{M}$ NAA added media for 1 month followed by transfer to normal embryo culture media, were compared with the control (culturing in normal embryo culture media). Three replicates with 15 plants in one replicate were used for each treatment. Development of new primary roots and plant growth was recorded.

\section{Data analysis}

Continuous data were analysed using GLM procedure and count data were analysed using CATMOD procedure in SAS statistical package (SAS Institute Inc., 1999).

\section{RESULTS AND DISCUSSION}

\section{Effect of genotype on in vitro embryo germination}

A significant difference in in vitro embryo germination was observed among cultivars used in this experiment (Table 1). The highest percentage of in vitro embryo germination was observed in the cultivar San Ramon Tall $(77.48 \%)$ and the lowest was observed in the cultivar King Coconut (52.5\%). Therefore, the effect of genotype can be considered as a factor contributing to variation of in vitro embryo germination of exotic varieties. Karun et al. (2002) also reported significant effect of the genotype and interaction between media composition and the genotype when four coconut cultivars (West Coast Tall, Laccadive Ordinary, Chowghat Orange Dwarf, and Malayan Yellow Dwarf) were cultured in embryo culture media used in the Philippines, India and France. Parallel studies conducted in Sri Lanka revealed significant difference of in vitro embryo germination between the cultivar Sri Lanka Tall (SLT) and PGD in modified $\mathrm{Y}_{3}$ medium (Weerakoon et al., 2002). In the present study cultivars which were not tested previously were selected. SNRT, which is a tall cultivar and SLT performed better than SLRD, RTB and PGD, which are dwarf and intermediate cultivars. Composition of the modified $\mathrm{Y}_{3}$ medium used in the present study was very similar to the media (Philippines, UPLB) used in the study by Karun et al. (2002). Cueto et al. (2012) confirmed the effects of genotype, age of nut, disinfection and storage procedures, screenhouse and tissue culture facilities on the establishment of embryos in culture and survival of embryo cultured seedlings during germplasm exchange programmes. Therefore, optimisation of culture media composition and culture conditions is required for different varieties to improve in vitro embryo germination. In addition, during germplasm exchange programmes more embryos can be collected and cultured from low germinating cultivars to get the desired number of plants from those cultivars.

Table 1: In vitro embryo germination of different cultivars

\begin{tabular}{lccc}
\hline Varieties & $\begin{array}{c}\text { Number } \\
\text { of embryos } \\
\text { cultured }\end{array}$ & $\begin{array}{c}\text { Number } \\
\text { of embryos } \\
\text { germinated }\end{array}$ & $\begin{array}{c}\text { Percentage } \\
\text { of embryo } \\
\text { germination }\end{array}$ \\
\hline SNRT & 85 & 66 & $77.48 \pm 15.2^{\text {a }}$ \\
SLRD & 86 & 57 & $67.28 \pm 23.8^{\mathrm{c}}$ \\
RTB & 80 & 42 & $52.5 \pm 6.5^{\mathrm{d}}$ \\
PGD & 86 & 62 & $71.85 \pm 8.1^{\mathrm{b}}$ \\
CV \% & & & 15.90 \\
\hline
\end{tabular}

Mean values followed by the same letter are not significantly different at $5 \%$ significant level

Table 2: Percentage of in vitro embryo germination of SLRD in different media

\begin{tabular}{lccl}
\hline Medium & $\begin{array}{c}\text { Number } \\
\text { of embryos } \\
\text { cultured }\end{array}$ & $\begin{array}{c}\text { Number } \\
\text { of embryos } \\
\text { germinated }\end{array}$ & $\begin{array}{l}\text { Percentage } \\
\text { of embryo } \\
\text { germination }\end{array}$ \\
\hline Liquid $75 \mathrm{~g} / \mathrm{L}$ sucrose & 90 & 51 & $56.66 \pm 10.6^{\mathrm{b}}$ \\
Liquid $60 \mathrm{~g} / \mathrm{L}$ sucrose & 86 & 52 & $60.46 \pm 7.5^{\mathrm{b}}$ \\
Solid $75 \mathrm{~g} / \mathrm{L}$ sucrose & 84 & 77 & $91.66 \pm 5.2^{\mathrm{a}}$ \\
Solid $60 \mathrm{~g} / \mathrm{L}$ sucrose & 90 & 83 & $92.22 \pm 5.0^{\mathrm{a}}$ \\
$\mathrm{CV} \%$ & & & 25.7 \\
\hline
\end{tabular}

Mean values followed by the same letter are not significantly different at $5 \%$ significant level 
Effect of germination medium on in vitro embryo germination of SLRD

A significant difference in in vitro embryo germination in liquid and solid medium was observed. A high in vitro embryo germination percentage was observed in solid medium compared to that in liquid medium (Table 2). However, the sucrose levels tested had no significant effect on in vitro embryo germination.

Shoot height in monthly intervals up to three months indicated a significant variation in shoot growth in different culture media (Table 3). A higher average shoot height was observed in solid medium compared to that in liquid medium. Moreover, $60 \mathrm{~g} / \mathrm{L}$ sucrose content in the medium favoured shoot growth by achieving the highest shoot height. Further, a better root growth was also observed in solid medium (data not statistically significant). Rillo and Cueto (2003) reported that at least one passage in solid medium and reduction of sugar during the growth and development phase improve in vitro growth in terms of earlier leaf and root formation, and higher percentage of cultures with simultaneous shoot and root formation. Karun et al. (2002) also reported hyperhydricity of embryos when germinated in liquid medium.

Table 3: Average shoot height of SLRD plants with time in different culture media

\begin{tabular}{lccc}
\hline Medium & $\begin{array}{c}\text { Average shoot height } \\
\text { after 1 month (mm) }\end{array}$ & $\begin{array}{c}\text { Average shoot height } \\
\text { after 2 months (mm) }\end{array}$ & $\begin{array}{c}\text { Average shoot height } \\
\text { after 3 months (mm) }\end{array}$ \\
\hline Liquid 75 g/L sucrose & $5.52 \pm 4.2^{\mathrm{c}}$ & $15.0 \pm 13.3^{\mathrm{d}}$ & $21.18 \pm 19.9^{\mathrm{c}}$ \\
Liquid $60 \mathrm{~g} /$ L sucrose & $5.52 \pm 4.4^{\mathrm{c}}$ & $15.15 \pm 15.7^{\mathrm{c}}$ & $19.65 \pm 22.7^{\mathrm{d}}$ \\
Solid 75 g/L sucrose & $6.64 \pm 4.2^{\mathrm{b}}$ & $27.8 \pm 8.3^{\mathrm{b}}$ & $41.04 \pm 14.3^{\mathrm{b}}$ \\
Solid 60 g/L sucrose & $7.5 \pm 3.9^{\mathrm{a}}$ & $29.26 \pm 9.8^{\mathrm{a}}$ & $48.26 \pm 29.3^{\mathrm{a}}$ \\
$\mathrm{CV} \%$ & 15.27 & 35.74 & 44.0 \\
\hline
\end{tabular}

Mean values followed by the same letter in a column are not significantly different at $5 \%$ significant level

Improvement in the percentage of in vitro germination may be due to better aeration of embryos in solid medium as embryos were placed upward up to about $2 / 3$ of its height buried in the medium. The effect of embryo placement in culture medium on in vitro germination has been studied by Areza et al. (1995) and a higher embryo germination was observed in solid medium compared to liquid medium. Further, Areza et al. (1995) indicated variations in germination percentage with embryo placement such as upward embryo placement in solid medium (93\%); downward embryo placement in solid medium (56\%); horizontal embryo placement in solid medium ( $88 \%$ ) and submerged in liquid medium (66\%).

\section{Effect of embryo maturity on in vitro germination of PGD}

The highest percentage of in vitro germination was observed in embryos of the 12 month old bunch $(97.67 \%)$, while the lowest percentage of germination was observed in the 10 month old bunch (52.17\%). These results clearly showed that in vitro embryo germination was affected by maturity of the nuts (Table 4 ).
A similar trend was observed in a previous experiment using a 9 month old bunch and 10 month old bunch from the cultivar Sri Lanka Tall (Weerakoon, 1999). An embryo germination percentage of $91.3 \%$ was observed in the 10 month old bunch compared to $27.3 \%$ in the 9 month old bunch (Weerakoon, 1999). Further, the results of an experiment conducted using embryos from $9^{\text {th }}$ to $11^{\text {th }}$ bunches of the cultivar Mapanget Tall

Table 4: In vitro germination of embryos of PGD at different maturity stages

\begin{tabular}{lccl}
\hline $\begin{array}{l}\text { Maturity stage } \\
\text { of embryo }\end{array}$ & $\begin{array}{c}\text { Number } \\
\text { of embryos } \\
\text { cultured }\end{array}$ & $\begin{array}{c}\text { Number } \\
\text { of embryos } \\
\text { germinated }\end{array}$ & $\begin{array}{c}\text { Percentage } \\
\text { embryo } \\
\text { germination }\end{array}$ \\
\hline 10 months & 46 & 24 & $52.17 \pm 21.7^{\mathrm{c}}$ \\
11 months & 42 & 35 & $83.33 \pm 13.3^{\mathrm{b}}$ \\
12 months & 43 & 42 & $97.67 \pm 8.0^{\mathrm{a}}$ \\
CV \% & & & 29.93 \\
\hline
\end{tabular}

Mean values followed by the same letter are not significantly different at $5 \%$ significant level. 
indicated $36.67,73.33$ and $78.33 \%$ embryo germination in $9^{\text {th }}, 10^{\text {th }}$ and $11^{\text {th }}$ bunch, respectively (Nurhaini, 2002). Therefore, during germplasm collection expeditions, nut maturity should be critically considered for successful embryo germination.

\section{Evaluation of hormonal influence in shoot and root development}

A significantly highest number of new primary roots developed (5.2) in seedlings cultured in $10 \mu \mathrm{M}$ BAP, $10 \mu \mathrm{M}$ kinetin and $200 \mu \mathrm{M}$ NAA added medium compared to that in the other treatments (Figure 2). Adding any growth hormone combination had a positive effect on rooting compared to the control (Table 5). Although the shoot height was lower $(272.0 \mathrm{~mm})$ in the above medium the number of leaves was the highest (3.6), which is a more favourable character for successful weaning. Therefore, considering the 3 parameters (number of new primary roots, shoot height, number of leaves), the addition of $10 \mu \mathrm{M}$ BAP, $10 \mu \mathrm{M}$ kinetin and $200 \mu \mathrm{M}$ NAA to embryo culture medium after 4 months enhances good root growth resulting in a plant suitable for weaning.

Ashburner et al. (1993) reported on the stimulation of primary root elongation when $100-300 \mu \mathrm{M}$ NAA was added to the final growth medium with increased sucrose level $(8 \%)$. In this experiment the sucrose content was kept at $6 \%$, which is the level used in all coconut embryo protocols (Weerakoon et al., 2002). A significant

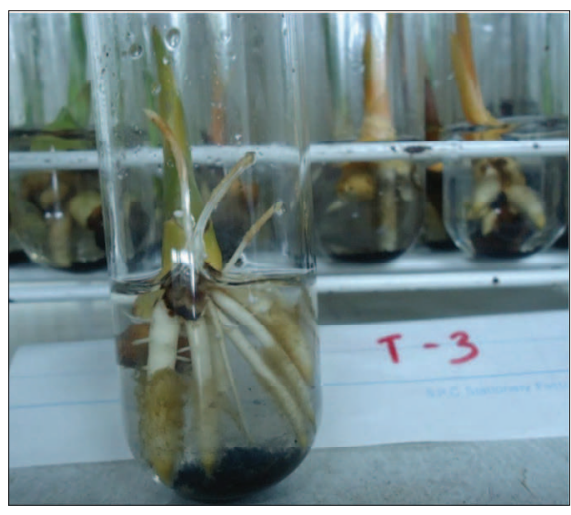

Figure 2: New primary root induction in $10 \mu \mathrm{M}$ BAP, $10 \mu \mathrm{M}$ Kinetin and $200 \mu \mathrm{M}$ NAA added medium

improvement was achieved by culturing in $10 \mu \mathrm{M}$ BAP, $10 \mu \mathrm{M}$ kinetin and $200 \mu \mathrm{M}$ NAA added medium for the initiation of many new primary roots compared to the other treatments. In preliminary experiments when $200 \mu \mathrm{M}$ NAA alone was tested, retardation of shoot growth (shoot height and number of leaves) was observed and this was also evident in the study by Ashburner et al. (1993). Shoot retardation due to root enhancement was also observed by IAA treatment (dipping shoots in IAA solution for 3 days followed by transfer to normal embryo culture media). This effect was compensated by adding $10 \mu \mathrm{M}$ BAP, $10 \mu \mathrm{M}$ kinetin at the same time of $200 \mu \mathrm{M}$ NAA addition.

Table 5: Root and shoot development of SLRD plants in different rooting treatments

\begin{tabular}{lccc}
\hline Medium & $\begin{array}{c}\text { Average new primary } \\
\text { roots after 3 months }\end{array}$ & $\begin{array}{c}\text { Average shoot height } \\
\text { after 3 months }(\mathrm{mm})\end{array}$ & $\begin{array}{c}\text { Average leaf number } \\
\text { after 3 months }\end{array}$ \\
\hline IAA & $2.5 \pm 0.7^{\mathrm{b}}$ & $242.0 \pm 20.3^{\mathrm{c}}$ & $2.4 \pm 0.93^{\mathrm{b}}$ \\
$\mathrm{BAP}+$ kinetin & $2.2^{\mathrm{c}} \pm 0.3^{\mathrm{c}}$ & $313.3 \pm 16.2^{\mathrm{a}}$ & $2.8 \pm 0.85^{\mathrm{b}}$ \\
$\mathrm{BAP}+$ kinetin + NAA & $5.2^{\mathrm{a}} \pm 0.9^{\mathrm{a}}$ & $272.0 \pm 19.2^{\mathrm{b}}$ & $3.6 \pm 0.98^{\mathrm{a}}$ \\
Y $_{3}$ & $0.5 \pm 0.7^{\mathrm{d}}$ & $321.8 \pm 19.8^{\mathrm{a}}$ & $2.8 \pm 0.77^{\mathrm{b}}$ \\
$\mathrm{CV} \%$ & $34.9^{\mathrm{a}}$ & 33.5 & $27.1^{\mathrm{C}}$ \\
\hline
\end{tabular}

Mean values followed by the same letter in a column are not significantly different at $5 \%$ significant level.

\section{CONCLUSION}

This study indicated that factors such as genotype, embryo maturity and culture medium affected in vitro germination of coconut embryos. Therefore, these factors have to be considered during embryo collection and culture. During embryo collection for varieties, which show low in vitro germination, more embryos have to be collected. Higher in vitro embryo germination can be achieved by culturing embryos from the 12 month old bunch. Embryo germination percentages could be further improved by culturing initially in solid media than in liquid media. By adding growth hormones plant growth and vigour could be improved with a significant increase in the number of primary roots and the number of leaves. 


\section{REFERENCES}

1. Areza M.B.B., Rillo E.P., Cueto C.A., Ebert A.W. \& Orense O.D. (1995). Effect of water quality, $\mathrm{pH}$ and state of the medium on growth and development of coconut embryos in vitro. Cord $\mathbf{X I}(1)$ : $1-12$.

2. Ashburner G.R., Thompson W.K. \& Burch J.M. (1993). Effect of $\alpha$-naphthaleneacetic acid and sucrose levels on the development of cultured embryos of coconut. Plant Cell, Tissue and Organ Culture 35: 157 - 163. DOI: http://dx.doi.org/10.1007/BF00032965

3. Assy-Bah B., Durand-Gasselin T. \& Pannetier C. (1987). Use of zygotic embryo culture to collect germplasm of coconut (Cocos nucifera L.). FAO/IBPGR Plant Genetic Resources Newsletter 71: 4-10.

4. Cueto C.A., Johnson V.B., Bourdeix R., Engelmann F., Kembu A., Konan J.L., Kouassi Kan M., Rivera R.L., Vidhanaarachchi V. \& Weise S.F. (2012). Technical guidelines for the safe movement and duplication of coconut (Cocos nucifera L.) germplasm using embryo culture transfer protocols. Available at http://www.cogentnetwork. org/past-projects/validation-of-a-coconut-embryo-cultureprotocol, Accessed 16 August 2013.

5. Fernando S.C. \& Gamage C.K. (1995). Clonal propagation of coconut: improved culture conditions for rhyzogenesis. Cocos 10: $20-25$.

6. Fernando S.C., Weerakoon L.K., Karunaratne S.M. \& Santha E.S. (2002). A cost effective medium for producing embryo-cultured coconut plants. Cocos 14: 45 - 52.

7. Karun A., Sajini K.K. \& Parthasarathy V.A. (2002). Increasing the efficiency of embryo culture to promote germplasm collecting in India. Coconut Embryo in vitro Culture: Part II (eds. F. Engelmann, P. Batugal \& J. Oliver), pp. 7 - 26. IPGRI-APO, Serdang, Malaysia.
8. Karunaratne S., Kurukulaarachchi C. \& Gamage C. (1985). A report on the culture of embryos of dwarf coconut, Cocos nucifera L. var. nana, in vitro. Cocos 3: $1-8$

9. Nurhaini M. (2002). Increasing the efficiency of embryo culture technology to promote coconut germplasm collecting, conservation and exchange in Indonesia. Coconut Embryo in vitro Culture: Part II (eds. F. Engelmann, P. Batugal \& J. Oliver), pp. 80 - 88. IPGRI-APO, Serdang, Malaysia.

10. Perera L., Russell J.R., Provan J. \& Powell W. (1999). Identification and characterization of microsatellite loci in coconut (Cocos nucifera L.) and the analysis of coconut populations in Sri Lanka. Molecular Ecology 8 (2): 344 346.

11. Perera L., Russell J.R., Provan J. \& Powell W. (2003). Studying genetic relationships among coconut varieties/ populations using microsatellite markers. Euphytica 132(1): $121-128$.

DOI: http://dx.doi.org/10.1023/A:1024696303261

12. Rillo E.P. \& Cueto C.A. (2003). Much improved coconut embryo culture protocol. Philippine Journal of Crop Science 28(1): 56.

13. Weerakoon L.K., Vidhanaarachchi V.R.M., Fernando S.C., Fernando A. \& Gamage C.K.A. (2002). Increasing the efficiency of embryo culture technology to promote coconut germplasm collecting and exchange in Sri Lanka. Coconut Embryo in vitro Culture: Part II (eds. F. Engelmann, P. Batugal \& J. Oliver), pp. 27 - 40. IPGRI-APO, Serdang, Malaysia.

14. Weerakoon L.K. (1999). Report of the tissue culture division. Annual Report (eds. C. Jayasekara, L.L.W. Somasiri, W.M.U. Fernando \& L.K. Weerakoon), pp. 173 - 186. Coconut Research Institute, Bandirippuwa Estate, Lunuwila. 